\title{
Effect of Insulin on Muscle Glutamate Uptake
}

\section{WHOLE BLOOD VERSUS PLASMA GLUTAMATE ANALYSIS}

\author{
T. T. Aoki, M. F. Brennan, W. A. Müller, F. D. Moore, and \\ G. F. CAHIIL, JR. \\ From the Joslin Diabetes Foundation and the Departments of Medicine and \\ Surgery, Harvard Medical School at Peter Bent Brigham Hospital, \\ Boston, Massachusetts 02115
}

\begin{abstract}
A в S T RAC T For decades, investigators concerned with protein metabolism in man have performed detailed amino acid analyses of human plasma obtained under a wide range of experimental situations. A large body of information has been used to calculated rates of protein synthesis and proteolysis. During the course of an investigation of the effect of intrabrachial artery infusion of insulin $(70 \mu \mathrm{U} / \mathrm{min}$ per $\mathrm{kg}$. body weight $)$ on glutamate uptake by human forearm muscle, it was discovered that plasma arterio-deep venous glutamate difference analysis failed to document any increase in the uptake of this amino acid, suggesting that insulin had little influence on glutamate uptake by muscle. However, whole blood glutamate analyses, performed on the same blood samples, revealed that $(a)$ the resting muscle uptake of glutamate is smaller than previously reported and $(b)$ insulin is capable of markedly increasing glutamate uptake by muscle from whole blood. Since the hematocrit was obtained on all samples, detailed analyses of the various compartments in which glutamate could be found were performed. It was determined that circulating blood cells have a dynamic role in glutamate transport. These data underscore the need for both whole blood and plasma amino acid analysis in investigations concerned with protein synthesis and/or amino acid flux, for analysis of plasma samples alone could be misleading as illustrated in the present study.
\end{abstract}

\section{INTRODUCTION}

Marliss, Aoki, Pozefsky, Most, and Cahill (1), using arterio-deep venous (A-DV) ${ }^{1}$ differences, have recently

Dr. Aoki is a U. S. Public Health Service Special Postdoctoral Fellow AM 43067-03; Dr. Brennan is a U. S. Public Health Service International Postdoctoral Fellow 1-F05-TWO-1756-01; and Dr. Müller is a Fellow of the Swiss National Fund.

Received for publication 5 May 1972 and in revised form 5 July 1972.

${ }^{1}$ Abbreviations used in this paper: A-DV, arteriodeep venous. reported that glutamate is removed from plasma by forearm muscle of normal humans to the extent of approximately $50 \mu$ moles/liter of plasma. In contrast, they noted that glutamine was added. This study stimulated interest into the mechanism(s), possibly hormonal in nature, influencing glutamate uptake by muscle.

Numerous in vitro studies $(2,3)$ have supported the role of insulin as a most important stimulus to amino acid uptake and protein synthesis. Furthermore, Pozefsky, Felig, Tobin, Soeldner, and Cahill (4) infused physiological amounts of insulin into the brachial artery of normal subjects and found a significant decrease in the release of a number of amino acids from forearm muscle. Of interest, however, is that in no instance was a striking uptake of any amino acid observed.

In man, insulin and amino acid levels are elevated for several hours after the ingestion of $150 \mathrm{~g}$ of protein (5). During this period of time and perhaps for a short time thereafter, insulin should induce a net uptake of amino acids by muscle to balance their release in the nonfed state. In order to approximate the duration of exposure of muscle to insulin after the ingestion of a meal while studying the effect of insulin alone on glutamate uptake by muscle, it was decided to infuse insulin into the brachial artery of normal human volunteers for a $90 \mathrm{~min}$ rather than the 26 min period used by Pozefsky et al. (4).

The suspicion of several investigators that the correct fluid to measure in studies of muscle amino acid metabolism was whole blood rather than plasma was also evaluated in the current investigation. In 1912, Van Slyke and Meyer (6), studying dogs fed $1 \mathrm{~kg}$ of meat, reported that the arterial whole blood $\alpha$-amino nitrogen content increased two- to threefold $5 \mathrm{hr}$ after the ingestion of the meat. In contrast, Frame (7) found that plasma (venous) $\alpha$-amino nitrogen rose only modestly $3-6 \mathrm{hr}$ after the ingestion of an eggnog meal. In retrospect, in order to derive a more accurate quantification of amino acid 
flux across muscle, both arterial and venous whole blood and plasma $\alpha$-amino nitrogen and/or amino acid determinations should have been performed in both investigations.

Finally, McMenamy, Lund, Neville, and Wallach (8) suggested that the cell: plasma ratio of any given amino acid is relatively constant, and that is primarily through the process of diffusion that changes in plasma amino acid levels would be reflected by coincident changes in circulating cellular amino acid content. Winter and Christensen (9) using human erythrocytes studied amino acid movement into and out of the red cell in in vitro experiments and concluded that the process is slow. The data of these two groups would lead one to conclude that the cellular constituents of blood, primarily red cells, play a relatively passive role in amino acid metabolism and that the long time-constant of diffusion precludes any important role to be played by the blood cells in amino acid transport from the gut to the periphery and vice versa. In order to assess the validity of this concept with respect to glutamate in particular, it was decided to perform both plasma and whole blood glutamate determinations and to compare the two.

\section{METHODS}

Five young healthy male volunteers were interviewed, examined, and submitted to biochemical screening to insure normality. All procedures and risks were carefully explained to each subject, and his informed consent was obtained. Several days before admission to the Surgical Research Unit at the Peter Bent Brigham Hospital, each was placed on a stable balanced diet. On the day after admission, and after an overnight fast, an incision was made in the antecubital fossa. Under direct vision, two 20 -gauge catheters were inserted into the brachial artery. One was directed proximally (for arterial blood sampling) and the other directed distally (for insulin infusion). A third catheter was inserted retrograde into a deep vein draining forearm muscle under direct vision. $5 \mathrm{~min}$ before blood sampling, a pediatric blood pressure cuff was applied to the wrist and inflated to $300 \mathrm{~mm} \mathrm{Hg}$ to cut off circulation to and from the hand. Paired A-DV blood samples for amino acids, glucose, insulin, $\mathrm{P}_{\mathrm{O}_{2}}, \mathrm{P}_{\mathrm{CO}_{2}}$, and $\mathrm{pH}$ were drawn at $-30,0,60,90,120$, 150,180 , and $240 \mathrm{~min}$. Two subjects, at the conclusion of the above procedure, were infused with a unit of fresh, panelselected whole blood, and on the following day, underwent another forearm procedure on the contralateral arm.

Preparation of blood samples, analyses and statistical methods have been previously described (10). Whole blood glutamate analyses were performed on filtrates prepared from whole blood samples deproteinized in equal volumes of chilled $30 \%(\mathrm{w} / \mathrm{v})$ perchloric acid (PCA) within $15 \mathrm{sec}$ of sampling. Preparation of plasma samples for glutamate determinations involved deproteinization (v/v) with $10 \%$ PCA. The same glutamate values were obtained when either acid was used, but $30 \%$ PCA shortened the time of centrifugation needed to obtain a clear filtrate of whole blood. The acid filtrates were promptly neutralized with potassium hydroxide to a $\mathrm{pH}$ of 7 and then stored at $-20^{\circ} \mathrm{C}$ until assayed. Prior laking of whole blood samples with 2 vol of water followed by protein precipitation produced identical glutamate values with those obtained with unlaked blood.

The enzymatic glutamate assay of Pagliara and Goodman (11) was used. Glutamate and NADH standard curves werc run in each assay and were identical. Recovery studies were close to $100 \%$ in either plasma or whole blood. Statistical analysis of plasma glutamate quality control samples over a 4 month period revealed a coefficient of variation of $5.5 \%$ $(31.66 \pm 1.75 \mu$ moles/liter of plasma, mean $\pm S D, n=6)$. All blood samples (paired A-DV, whole blood, and plasma) from a given experiment were analyzed for glutamate in the same assay.

Arterial and venous $\mathrm{P}_{\mathrm{O}_{2}}, \mathrm{P}_{\mathrm{CO}_{2}}$, and $\mathrm{pH}$ determinations were performed within several minutes of sampling on a Radiometer $\mathrm{pH}, \mathrm{P}_{\mathrm{O}_{2}}, \mathrm{P}_{\mathrm{CO}_{2}}$ meter (model $\mathrm{PHM}$ 71). The precautions outlined by Andres, and colleagues (12) were observed to minimize mechanical distortions of flow in the forearm. Flow was not directly measured, as the interpolative problem of equating either arterial or venous blood flow measurements obtained using the dye dilution technique with true muscle blood flow persists. The establishment of unchanging arterial and deep venous $\mathrm{P}_{\mathrm{o}_{2}}, \mathrm{P}_{\mathrm{co}_{2}}, \mathrm{pH}$, hematocrit, and hemoglobin content, together with the unvarying position of the venous-oxygen dissociation curve were considered indicative of the relative constancy of muscle blood flow. No attempt was made to express amino acid flux in terms of unit muscle mass. However, for convenience, when the venous level of a given substrate is less than the arterial level, the term uptake will be used. When the reverse is true, the term release will be used. Finally, our previous experience has shown that the various dyes used in the dye dilution technique interfere with spectrophotometric and fluorometric analyses of substrates.

The amount of insulin (Crystalline zinc insulin, Eli Lilly \& Co., Indianapolis, Ind.) infused in each subject was $70 \mu \mathrm{U} /$ $\mathrm{kg}$ per min with an infusion volume of $4.58 \mathrm{ml} / \mathrm{hr}$ delivered by a Harvard infusion pump (Harvard Apparatus Co. Inc., Millis, Mass.) for a total of $90 \mathrm{~min}$. Salt-poor human albumin (E. R. Squibb \& Sons, Princeton, N. J.), $250 \mathrm{mg} / 100$ $\mathrm{ml}$, was added to minimize insulin loss due to adhesion to the glass syringes and plastic tubing. During the last $30 \mathrm{~min}$ of the 90 min infusion period, a pediatric blood pressure cuff was applied to the wrist and inflated to $300 \mathrm{~mm} \mathrm{Hg}$ which eliminated the hand from the perfusion circuit while simultaneously insuring a high concentration of insulin within the forearm.

Since a macrohematocrit was obtained in duplicate on each blood sample, it was possible to calculate the glutamate contribution of the plasma alone in a liter of whole blood, i.e., (100-hematocrit) (0.01) ( $\mu$ moles/liter of plasma)= plasma contribution. (Reference to plasma glutamate henceforth will refer to the plasma contribution in a liter of whole blood rather than to a liter of plasma.) Thus, if the hematocrit of a given sample was 40 , then $600 \mathrm{ml}$ of plasma are present in a liter of that blood. If plasma glutamate is $100 \mu$ moles/ liter of plasma, then the actual contribution of the plasma would be $100 \mu$ moles $\times 0.6$ or $60 \mu$ moles/liter of whole blood. It is now possible to calculate the contribution of the cellular components of blood (cells) by using the formula:

Whole blood glutamate - plasma glutamate $=$ cell glutamate

Some plasma is trapped with the cells when the hematocrit is taken, but this amount is small (13) and can be ignored.

Finally, in order to evaluate the possibility that glutamate moved from either the plasma into cells or vice versa in the sampling tube, $576 \mathrm{nmoles}$ of glutamate was added to $24 \mathrm{ml}$ of freshly drawn blood, $12 \mathrm{ml}$ of which was immediately processed while the remaining $12 \mathrm{ml}$ of blood was allowed to 
TABLE I

Blood Cell Glutamate: Direct Assay vs. Calculated Values

\begin{tabular}{ccc}
\hline Sample & Assayed & Calculated \\
\hline 1 & 104 & 99 \\
2 & 123 & 121 \\
3 & 98 & 96 \\
4 & 108 & 115 \\
5 & 104 & 100 \\
6 & 119 & 127 \\
7 & 97 & 100 \\
8 & 112 & 114 \\
& $108 \pm 3^{*}$ & $109 \pm 4^{*}$
\end{tabular}

Assayed values (micromoles/liter whole blood) are from direct analysis of the blood cell fraction. Calculated values are derived by subtracting the plasma from the whole blood values. The two groups were not significantly different.

* mean \pm SEM.

stand at room temperature for $3 \mathrm{hr}$ and then processed. In addition, another $24 \mathrm{ml}$ of blood, drawn at the same time, was separated and handled in an identical manner except that an equivalent volume of saline was added in lieu of glutamate.

\section{RESULTS}

Comparison of the results of direct assays of the cellular constituents of eight different blood samples with the corresponding calculated cell content of glutamate are shown in Table I. The means and standard errors of the mean of the two groups are virtually identical. In addition, paired $t$ analysis (assayed vs. calculated) showed that the two groups were not significantly different $(t=-0.50 \mathrm{n}=8)$. Of greater interest, when glutamate is added to fresh whole blood samples (Table II), the added glutamate appears in the plasma compartment rather than in the cells when the samples are processed immediately. This situation still obtains when matching blood samples, standing at room temperature $\left(27^{\circ} \mathrm{C}\right)$ for $3 \mathrm{hr}$, are analyzed. When saline is added to

TABLE II

Recovery and Stability of Plasma and Blood Cell Glutamate

\begin{tabular}{lccccc}
\hline & \multicolumn{2}{c}{ Immediate } & & \multicolumn{2}{c}{ After $3 \mathrm{hr}$} \\
\cline { 2 - 3 } \cline { 5 - 6 } Processing & Control & $\begin{array}{c}\text { Added } \\
\text { glutamate* }\end{array}$ & & Control & $\begin{array}{c}\text { Added } \\
\text { glutamate }\end{array}$ \\
\hline $\begin{array}{c}\text { Whole blood } \\
\mu \text { moles }\end{array}$ & 142 & 167 & & 140 & 160 \\
$\begin{array}{c}\text { Plasma } \\
\mu \text { moles }\end{array}$ & 29 & 50 & & 31 & 51 \\
$\begin{array}{c}\text { Blood cells } \\
\mu \text { moles } \\
\text { Blood cells (calculated) } \\
\mu \text { moles }\end{array}$ & 115 & 114 & & 106 & 106 \\
\hline
\end{tabular}

* Glutamate was added (24 $\mu$ moles/liter of whole blood) before centrifugation to samples undergoing immediate analysis and at 0 time in those left standing for $3 \mathrm{hr}$ at $27^{\circ} \mathrm{C}$. Each value is the mean of three experiments.

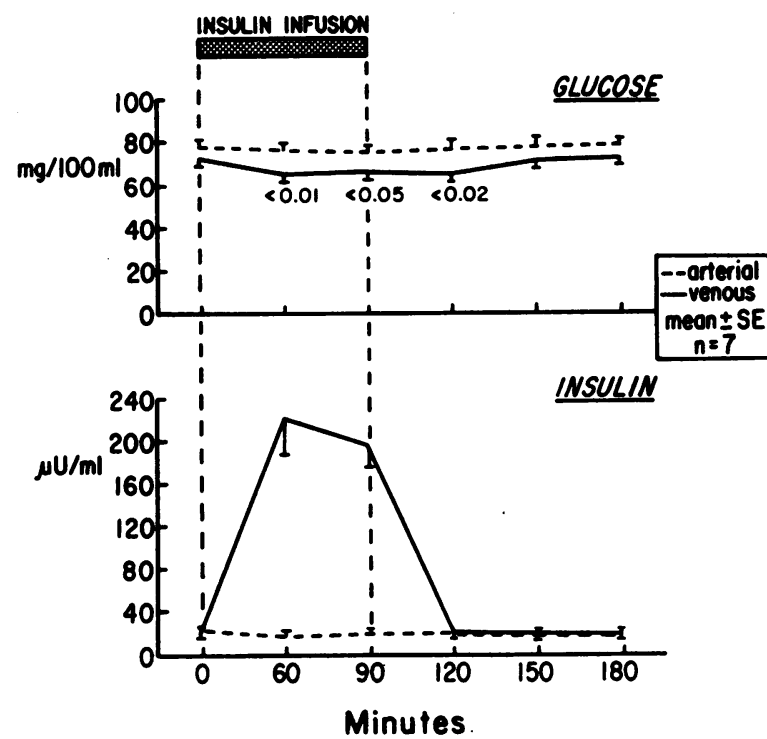

FIGURE 1 The effect of forearm insulinization on glucose uptake. Deep venous-effluent immunoreactive insulin values (mean ISEM) rose promptly to high levels during the insulin infusion period and then promptly returned to base line following the cessation of the infusion. Arterial insulin levels, reflecting the general circulation, did not change significantly during the studies. Glucose uptake increased significantly at 60,90 , and at $120 \mathrm{~min}$.

control blood samples, intracellular glutamate does not shift into plasma, even after standing at room temperature. Thus the changes in glutamate content found in the venous blood samples obtained from the current forearm studies cannot be attributed to any shift of glutamate

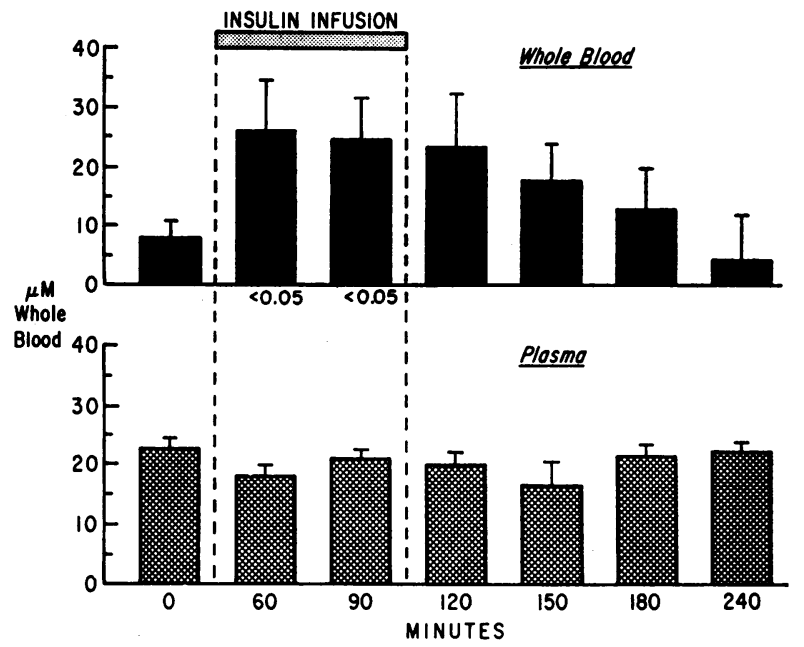

Figure 2 The effect of insulin on glutamate uptake by forearm muscle. Whole blood and plasma A-DV glutamate differences (mean \pm SEM). Note the increase in uptake by muscle revealed when whole blood glutamate determinations were performed and the failure of plasma glutamate determinations to show the same change. 


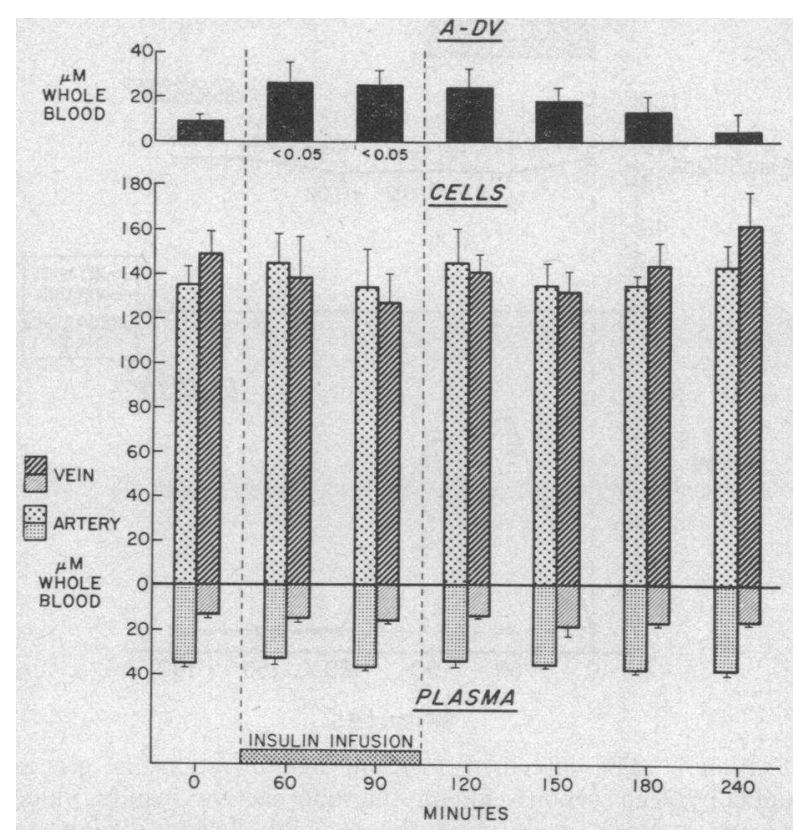

Figure 3 Detailed analysis (mean \pm SEM) of arterial and deep venous blood samples before, during, and after forearm insulinization $(n=5)$. Note the increase in venous cell glutamate (calculated) at $0 \mathrm{~min}$. During the insulin infusion, venous cell glutamate decreases, indicating a net release of glutamate from the circulating blood cells. Arterial whole blood and plasma glutamate values did not change significantly during the procedure.

between plasma and blood cells that occurs while the samples are standing at room temperature after collection.

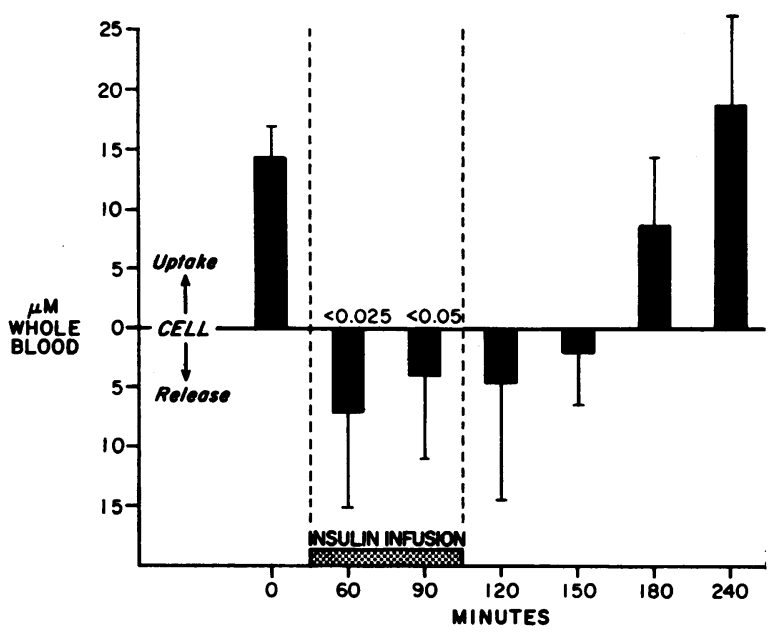

Figure 4 Blood cell glutamate dynamics. At rest, there is a net movement of glutamate from arterial plasma into the cells (mean \pm SEM). At $60,90,120$, and $150 \mathrm{~min}$, there is a net movement of glutamate out of the cells. At 180 and $240 \mathrm{~min}$, there is a gradual return to base line conditions.
TABLE III

\begin{tabular}{rccccc}
\hline Time & $\mathrm{n}$ & $\mathrm{Po}_{2}(\mathrm{~A}-\mathrm{DV}) *$ & $\mathrm{PcO}_{2}(\mathrm{~A}-\mathrm{DV}) *$ & $\begin{array}{c}\text { Arterial } \\
\mathrm{pH}^{*}\end{array}$ & $\begin{array}{c}\text { Venous } \\
\mathrm{pH}\end{array}$ \\
\hline $\min$ & & $m m \mathrm{Hg}$ & $m m \mathrm{Hg}$ & & \\
0 & 8 & $57.6 \pm 4.6$ & $8.0 \pm 1.6$ & $7.38 \pm 0.02$ & $7.36 \pm 0.02$ \\
60 & 8 & $61.9 \pm 3.4$ & $8.2 \pm 1.1$ & $7.38 \pm 0.02$ & $7.35 \pm 0.01$ \\
90 & 8 & $62.9 \pm 3.0$ & $8.8 \pm 1.0$ & $7.39 \pm 0.02$ & $7.35 \pm 0.02$ \\
120 & 8 & $60.6 \pm 2.9$ & $8.3 \pm 1.2$ & $7.38 \pm 0.02$ & $7.34 \pm 0.02$ \\
150 & 8 & $63.4 \pm 4.6$ & $8.1 \pm 1.0$ & $7.39 \pm 0.04$ & $7.35 \pm 0.02$ \\
180 & 8 & $58.0 \pm 3.4$ & $6.6 \pm 1.5$ & $7.38 \pm 0.03$ & $7.35 \pm 0.02$ \\
240 & 4 & $\mathbf{6 7 . 0} \pm 5.7$ & $7.8 \pm 1.3$ & $7.40 \pm 0.04$ & $7.35 \pm 0.02$
\end{tabular}

Neither $\mathrm{A}-\mathrm{DV} \mathrm{PO}_{2}$ and $\mathrm{P}_{\mathrm{CO}_{2}}$ differences nor arterial and venous $\mathrm{pH}$ values changed significantly during the insulin infusion.

$*$ Mean \pm SEM

The intra-arterial infusion of insulin $(70 \mu \mathrm{U} / \mathrm{kg}$ per $\mathrm{min}$ ) resulted in high levels of insulin within the forearm (Fig. 1). Venous-effluent concentrations rose from $20 \pm 8$ to $223 \pm 33$ at $60 \mathrm{~min}$ and $187 \pm 24$ at $90 \mathrm{~min}$ (mean \pm SEM, $\mu \mathrm{U} / \mathrm{ml}$ ). Arterial levels of insulin; reflecting the levels of this hormone in the general circulation, did not change during the experimental period. As expected glucose uptake increased significantly at 60,90 , and $120 \mathrm{~min}$ (Fig. 1).

In Fig. 2, A-DV differences of plasma and whole blood glutamate are shown. The control A-DV values for plasma glutamate (22.6 $\pm 5 \mu$ moles/liter whole blood) are comparable with the values previously reported from this laboratory (1) when the latter values are adjusted as previously described. In contrast, whole blood A-DV glutamate differences show a much smaller resting uptake at 0 time $(8.4 \pm 2.8 \mu$ moles/liter whole blood $)$.

During the period of insulin infusion, plasma A-DV differences for glutamate failed to show any increased uptake of this amino acid, while in sharp contrast, whole blood A-DV glutamate differences increased significantly at $60 \mathrm{~min}(26 \pm 8.7)$ and at $90 \mathrm{~min}(24.8 \pm 6.9)$ and grad-

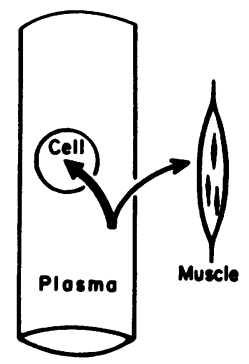

CONTROL

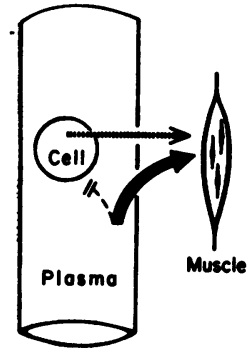

INSULIN

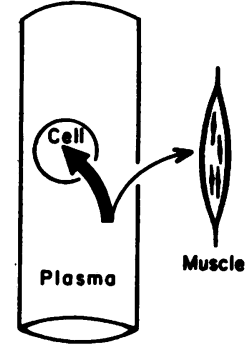

POSTINSULIN
FIGURE 5 Schematic representation of the changes of glutamate flow between plasma, blood cells, and muscle. At rest, there is a shift from arterial plasma into both blood cells and muscle. During the insulin infusion, glutamate shifts out of both the blood cells and plasma into muscle. And finally, there is a gradual return to base line. 
ually returned thereafter to base line values (Fig. 2). When the blood cell glutamate content (arterial and venous) is calculated, the differences between the two determinations are resolved. In Figs. 3-5, it can be seen that at rest, there is a shift of glutamate from arterial plasma into both cells and muscle, and that here is a net uptake of glutamate to the extent of $8.4 \pm 2.8 \mu$ moles/liter whole blood across muscle. During the insulin infusion, there is a shift out of both cells and plasma compartments into muscle. By $240 \mathrm{~min}, \mathrm{~A}-\mathrm{DV}$ glutamate differences have returned to control values.

As seen in Table III, neither A-DV differences for oxygen and carbon dioxide nor arterial and venous $\mathrm{pH}$ values changed significantly during the course of the experiments. In addition, the arterial and venous hematocrits, the venous hemoglobin content, and the position of the venous-oxygen dissociation curve did not change during the course of the studies. While flow and hence flux cannot be ascertained from these data alone, it seems reasonable to assume that flow did not change appreciably during the performance of these investigations.

\section{DISCUSSION}

Insulin is able to effect a striking increase in glutamate uptake by muscle (Fig. 2). The reason for the apparent failure of Pozefsky et al. (4) to demonstrate uptake by muscle of other amino acids is suggested by the current investigation. Inspection of plasma A-DV glutamate differences would lead one to conclude that insulin has little if any effect on glutamate uptake by muscle, whereas analysis of whole blood A-DV glutamate differences of the same samples show the reverse.

Fig. 5 schematically depicts glutamate in arterial plasma entering both muscle and blood cells in almost equal amounts, and it is that portion which enters muscle that determines the actual resting uptake of glutamate by muscle and which is measured by whole blood determinations. (Determinations of plasma glutamate levels alone are misleading in this instance, for they fail to show that part of the plasma A-DV difference is attributable to a shift from arterial plasma to blood cells.) In the presence of insulin, however, arterial plasma glutamate is no longer partially diverted to the blood cells but is redirected in its entirety to muscle, and, in addition, is accompanied by a smaller amount of glutamate which is derived from the blood cells themselves. It is this change in the behavior of the blood cells with respect to glutamate that enables the dramatic increased uptake of this amino acid by muscle to occur. Thus, insulin affects both the direction and magnitude of the dynamic interplay that exists with respect to glutamate, and perhaps other amino acids as well, between plasma, blood cells, and muscle with the blood cells playing a pivotal role.
The cellular constituents of blood, presumably the red cells, as evidenced by these data on glutamate, appear to play a dynamic rather than a static role in amino acid transport. Indeed, these cells may represent a labile pool of amino acids that is replenished in the splanchnic bed after meals and partially depleted at the periphery (muscle) in the presence of increased insulin levels. Support for this concept, with respect to glutamate in particular, stems in part from the work of Marliss et al. (1) who have shown that the splanchnic bed is indeed a site of glutamate production and from the current investigation in which increased glutamate uptake by muscle occurs in the presence of elevated levels of insulin.

The time constant for the taking up and release of amino acids by the blood cells appears to be quite brief (a single passage through muscle), and this short time constant may explain the findings of both McMenamy et al.(8) and Winter and Christensen (9). The erythyrocytes studied in both investigations were separated from venous blood obtained from postabsorptive, healthy, well-nourished subjects, i.e., the plasma and cells were already optimally equilibrated with respect to amino acids.

It also seems reasonable to conclude that the rapid shift of amino acids into and out of the blood cells is mediated through an active, energy-requiring process rather than to simple diffusion. But precisely where and how insulin is able to effect this shift of amino acids from blood cell to muscle cell is not revealed by the current study. It is interesting to speculate that insulin somehow sensitizes the blood cell membrane such that when it passes through muscle actively synthesizing protein, a region of amino acid need, it is no longer able to maintain a gradient and subsequently actively releases amino acids into the plasma and muscle. A second possibility is that insulin activates a second messenger within the muscle bed that triggers the release of amino acids from the circulating blood cells.

Finally, it has been suggested (14) that the time of protein synthesis in man is relatively brief when compared with the time spent in breaking down protein for glucose synthesis by the liver. Data from the current study support this concept, for despite high levels of insulin within the forearm, increased glutamate uptake appeared to be confined to the period of infusion and for approximately $90 \mathrm{~min}$ thereafter, a total of $3 \mathrm{hr}$.

In conclusion, insulin is clearly able to effect an increase in glutamate uptake by muscle. This response to insulin is detectable only when whole blood and not when plasma determinations are performed. Circulating blood cells, primarily erythrocytes, may constitute a labile pool of amino acids, taking up and transporting amino acids from regions of plenty (primarily splanchnic bed) to regions of amino acid need (muscle). Whole blood and 
plasma A-DV differences as well as flow measurements should be obtained whenever amino acid flux data are desired, for analysis of plasma samples alone may be quite misleading, as it was in the current investigation.

\section{ACKNOWLEDGMENTS}

We wish to express our deep appreciation of the gracious and accurate work of Mrs. Dzidra Rumba, Miss Margaret Ball, and Mmes. Adacie Allen, Patricia Hatch, and Velta Ramolins.

This study was supported in part by U. S. Public Health Service Grants AM-15191 and HE13872, the John A. Hartford Foundation, and the U. S. Army Research and Development Command DA-49-193-MD-2337.

\section{REFERENCES}

1. Marliss, E. B., T. T. Aoki, T. Pozefsky, A. S. Most, and G. F. Cahill, Jr. 1971. Muscle and splanchnic glutamine and glutamate metabolism in postabsorptive and starved man. J. Clin. Invest. 50: 814.

2. Manchester, K. L. 1970. The control by insulin of amino acid accumulation in muscle. Biochem. J. 117: 457.

3. Manchester, K. L., and F. G. Young. 1958. The effect of insulin on incorporation of amino acids into protein of normal rat diaphragm in vitro. Biochem. J. 70:353.

4. Pozefsky, T., P. Felig, J. D. Tobin, J. S. Soeldner, and G. F. Cahill, Jr. 1969. Amino acid balance across tissues of the forearm in postabsorptive man. Effects of insulin at two dose levels. J. Clin. Invest. 48: 2273.

5. Müller, W. A., G. R. Faloona, E. Aguilar-Parada, and R. H. Unger. 1970. Abnormal alpha-cell function in diabetes. Response to carbohydrate and protein ingestion. N. Engl. J. Med. 283 : 109.

6. Van Slyke, D. D., and G. M. Meyer. 1912. The aminoacid nitrogen of the blood. Preliminary experiments on protein assimilation. J. Biol. Chem. 12: 399.

7. Frame, E. G. 1958. The levels of individual free amino acids in the plasma of normal man at various intervals after a high-protein meal. J. Clin. Invest. 37: 1710.

8. McMenamy, R. H., C. C. Lund, G. J. Neville, and D. F. H. Wallach. 1960. Studies of unbound amino acid distributions in plasma, erythrocytes, leukocytes and urine of normal human subjects. J. Clin. Invest. 39: 1675.

9. Winter, C. G., and H. N. Christensen. 1964. Migration of amino acids across the membrane of the human erythrocyte. J. Biol. Chem. 239: 872.

10. Marliss, E. B., T. T. Aoki, R. H. Unger, J. S. Soeldner, and G. F. Cahill, Jr. 1970. Glucagon levels and metabolic effects in fasting man. J. Clin. Invest. 49: 2256.

11. Pagliara, A. S., and A. D. Goodman. 1969. Elevation of plasma glutamate in gout. Its possible role in the pathogenesis of hyperuricemia. N. Engl. J. Med. 281 : 767.

12. Andres, R., K. L. Zierler, H. M. Anderson, W. N. Stainsby, G. Cader, A. S. Ghrayyib, and J. L. Lilienthal, Jr. 1954. Measurement of blood flow and volume in the forearm of man; with notes on the theory of indicator-dilution and on production of turbulence, hemolysis, and vasodilatation by intra-vascular injection. $J$. Clin. Invest. 33 : 482.

13. Chaplin, H., Jr., and P. L. Mollison. 1952. Correction for plasma trapped in the red cell column of the hematocrit. Blood J. Hematol. 7 : 1227.

14. Cahill, G. F., Jr. 1971. Physiology of insulin in man. Diabetes. $20: 785$. 